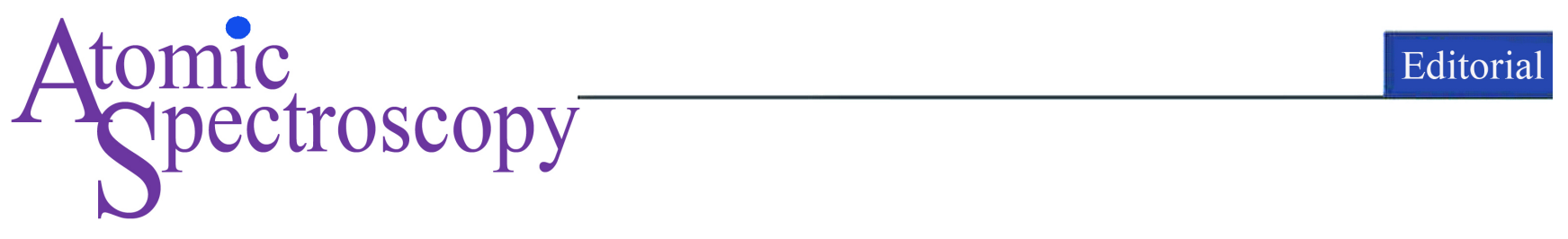

\title{
Metallomics in Multidisciplinary Research and the Analytical
}

\section{Advances}

\author{
Yu-Feng $\mathrm{Li},{ }^{\mathrm{a}, \mathrm{b}, *}$ and Hongzhe Sun ${ }^{\mathrm{c}}$ \\ ${ }^{a}$ CAS-HKU Joint Laboratory of Metallomics on Health and Environment, \& CAS Key Laboratory for Biomedical Effects of Nanomaterials and \\ Nanosafety, \& Beijing Metallomics Facility, \& National Consortium for Excellence in Metallomics, Institute of High Energy Physics, Chinese Academy of \\ Sciences, Beijing 100049, P.R. China \\ ${ }^{\mathrm{b}}$ University of Chinese Academy of Sciences, Beijing 100049, P.R. China \\ ${ }^{c}$ Department of Chemistry, \& HKU-CAS Joint Laboratory of Metallomics on Health and Environment, The University of Hong Kong, Hong Kong Special \\ Administrative Region, P.R. China
}

Received: July 28, 2021; Revised: August 13, 2021; Accepted: August 16, 2021; Available online: August 19, 2021.

DOI: 10.46770/AS.2021.108

\section{INTRODUCTION}

Metallomics is a research field focusing on the systematic study of the interactions and functional connections of metallome with genes, proteins, metabolites, and other biomolecules within organisms. ${ }^{1-5}$ The field provides a global and systematic understanding of the metal uptake, trafficking, role and excretion in biological systems, and potentially to be able to predict all of these in silico using bioinformatics. ${ }^{6,7}$

The term "metallomics" was coined by Haraguchi ${ }^{2}$ in 2002 as "integrated biometal science" while the term "metallome" was used by RJP Williams ${ }^{3}$ in 2001, referring to "an element distribution or a free element content in a cellular compartment or a whole cell." Metallomics has also gained increasing attention among scientists working outside of the biological fields, such as in nanoscience, environmental science, agriculture science, biomedical science, food science, geoscience, toxicological science, materials science, and analytical science. , 8-14 $^{-14}$

\section{METALLOMICS IN MULTIDISCIPLINARY RESEARCH}

The convergence of metallomics with other research fields has led to new research directions (Fig. 1). Nanometallomics was initiated as a branch of metallomics in nanoscience in $2010^{15}$. It involves the global study of the biological effects of metal-related nanomaterials. ${ }^{16,17}$ The study of the effects of metal(loid)-based nanomaterials on the homeostasis of essential elements is also considered nanometallomics, and this research plays a central

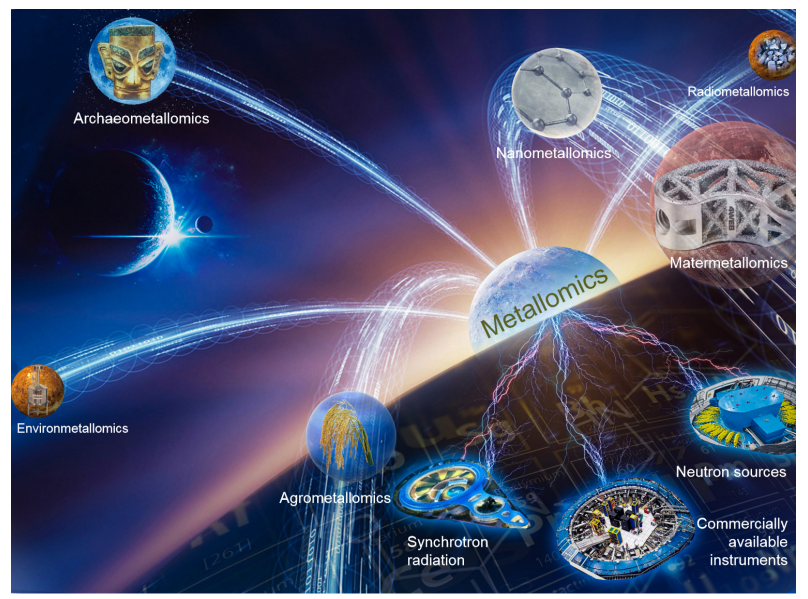

Fig. 1 The branches of metallomics and analytical techniques. Nanometallomics, environmetallomics, agrometallomics, metrometallomics, clinimetallomics, medimetallomics, radiometallomics, matermetallomics, archaeometallomics, geometallomics, and astrometallomics are proposed as new fields. Large scientific facilities like synchrotron radiation and neutron and muon sources provide cutting-edge techniques for metallomics together with commercially available instruments like (MC)-ICP-MS.

role in nanotoxicology. ${ }^{18}$ Recently, nanometallomics was further expanded to include non-metallic nanomaterials such as carbonand silicon-based nanomaterials for elemental homeostasis in biological systems. ${ }^{19}$

In environmental science, understanding the roles of environmental pollutants, such as metal(loid)s, on human health is highly desirable. ${ }^{20}$ In 2006 , "environmental metallomics" was proposed to monitor metal pollution using metalloproteins. ${ }^{21}$ 
Environmetallomics was first proposed as an environmental branch of metallomics in 2016. ${ }^{22}$ It was defined as the study on "(i) the entirety of metal and metalloid species that can induce toxic effects on living organisms at an environmentally relevant concentration range; (ii) all metals and metalloids within a biological system which homeostasis could be directly or indirectly interfered and regulated to induce potential adverse effects. ${ }^{23}$ " However, studies on the effects of other environmental pollutants, such as persistent organic pollutants, on elemental homeostasis are also desired to be included in environmetallomics.

In agriculture science, it is necessary to understand the roles of metal(loid)s in ensuring the yield and quality of agricultural products and food safety for humans. Agrometallomics was recently proposed as an interdisciplinary area between agriculture science and metallomics to fulfill this purpose. ${ }^{24}$

In this issue, we are very pleased to see more branches of metallomics such as metrometallomics, ${ }^{25}$ clinimetallomics, ${ }^{26}$ radiometallomics, ${ }^{27}$ matermetallomics, ${ }^{28}$ and archaeometallomics $^{29}$ have been proposed, reflecting the prosperity of the metallomics field.

Metrometallomics, coined by Feng et $a .^{25}$, is the qualitative and quantitative measurement of metallic analytes in metrological science, including the establishment of reference methods with uncertainty evaluation and the development of certified reference materials. In their review, the authors discussed the application of ICP-MS for the development of certified reference materials of metalloproteins, suggesting that metrometallomics can be a useful tool in metrological science.

Li et al. ${ }^{26}$ proposed the application of clinimetallomics for disease diagnosis using clinical samples such as urine, blood, and tissue. In their research article, $\mathrm{Li}$ et al. established an HPLC-ICP-MS method for the determination of arsenic species in urine samples from patients with arsenism. The arsenic species in urine were monitored after clinical treatment, revealing that As(III) was excreted.

Radioactive metallic elements can cause radiation damage and heavy-metal pollution, posing health risks to humans. Zhao et $a l .{ }^{27}$ used radiometallomics to unravel the ecological and biological metabolism and behaviors of radioactive metal elements. In their review, Zhao et al. studied uranium in environmental matrices using conventional and synchrotron radiation-based radiometallomics methods. However, systematic studies on the biological effects of radio-medicines and radio-tracers can also be regarded as radiometallomics.

Materials are important for societal development, and novel materials are always desired for various applications. Materials genomics is a useful tool for the development of new materials. ${ }^{30}$ In this issue, Wang et al. ${ }^{28}$ proposed matermetallomics as a tool to clarify the role and function of metal elements in materials, focusing on the study of the distribution, species, and concentration of metal elements in micro and macro structures. This is the first attempt to apply metallomics outside the life-related sciences.

Cultural relics are leftovers from ancient human activities, and are important for archeological research. Feng et al. ${ }^{29}$ proposed archaeometallomics as a tool to systematically study the role of trace elements in cultural relics. They studied the origin, dating, color mechanism, and firing technology of ancient ceramics through archaeometallomics.

In addition to their role in the above-mentioned branches of metallomics, metal(loid)s play an interesting role in the study of evolution and the origin of life, which involves the examination of geological samples such as fossils. ${ }^{31}$ In this case, geometallomics, which combines metallomics with geological science, can be utilized. One example is a study on the elemental signatures in teeth from the extinct Australopithecus africanus, which found that dietary stress contributed to the disappearance of this genus. ${ }^{32}$ Furthermore, the exploration of extraterrestrial life combined with metallomics is called astrometallomics. It is an innovative combination of metallomics and astronomy that aids in the search for extraterrestrial life, including the increasing cosmic explorations to the Moon and Mars. ${ }^{33}$

\section{THE ANALYTICAL ADVANCES IN METALLOMICS}

High-throughput analytical methods for quantification, speciation, distribution, and structure analysis are required in metallomics studies. ${ }^{34}$ Isotopic analysis is attracting increasing attention in metallomics. ${ }^{35}$ In this issue, Yuan et al. ${ }^{36}$ reported an accurate method for analyzing iron isotopes in iron-dominated minerals using excimer laser ablation MC-ICP-MS. Beauchemin et al. ${ }^{37}$ applied a continuous on-line leaching method with ICP-MS using a ${ }^{206} \mathrm{~Pb} /{ }^{207} \mathrm{~Pb}$ isotopic ratio for source identification of the bio-accessible lead.

In addition to the commercially available instruments showcased by contributors in this issue $25,26,28,36,37$, large scientific facilities also play a vital role in providing cutting-edge techniques for metallomics. ${ }^{8,38}$ For example, in this issue, synchrotron radiation-based radiometallomics was covered by Zhao et al. $^{27}$ and archaeometallomics by Feng et al. ${ }^{29}$. The application of nuclear analytical techniques, including synchrotron radiation, neutron sources, and radioactive nuclides, has been summarized in reports on nanometallomics for nanotoxicological study. ${ }^{39,40}$ Muonic X-rays produced in muon facilities have also been used for elemental and imaging analysis. Their merits include being nondestructive and sensitive to light elements and depth analysis, and they have been used to detect $\mathrm{Li}$ in Li-ion batteries. ${ }^{41}$ 
Cells are the basic structural and functional units of living organisms. Owing to the heterogeneity and diversity of individual cells, single-cell analysis is of great importance. Wang et $\mathrm{al}^{42}$ quantified gold nanoparticles in single cells with time-resolved ICP-MS, a process which can be regarded as single-cell metallomics. ${ }^{43}$ Single-cell-based mass cytometry represents a breakthrough technique for the biomedical sciences and precision medicine. Furthermore, the study of the spatial distribution (the 2D, 3D, and even 4D) of metallomes is called spatial metallomics, and this has been applied in nanotoxicological research. ${ }^{44}$

Comparative metallomics, proposed by Szpunar, ${ }^{45}$ involves the monitoring of changes in the metallome as a function of time and exposure to external stimuli. It has been applied to screen the neurotoxicity of chemicals such as mercury. ${ }^{46}$ Comparative nanometallomics was recently proposed as a new tool for nanosafety evaluation and has been showcased using selenium nanoparticles as an example. ${ }^{47}$

With the ongoing COVID-19 pandemic caused by SARS-CoV-2, the health of human around the world has been under severe threat. Although RT-PCR and antigen tests are used for the screening of COVID-19, they have drawbacks like high cost, long processing time and false-negative results of these methods, etc. Comparative metallomics have the merits of high throughput, low risk of cross-infection, less cost and more readily availability. In this issue, Li et al. ${ }^{48}$ propose to apply metallomics for the screening of COVID-19 and drug development and present an operational work scheme.

Medimetallomics combines metallomics with medical science. An excellent example of this is a study aimed at discovering drugs to treat the emerging COVID-19 disease. Sun et al. ${ }^{49}$ found that ranitidine bismuth citrate suppressed SARS-CoV-2 replication and relieved virus-associated pneumonia in Syrian hamsters by disrupting the functions of helicase and other essential viral enzymes. Selenium was also found to have antiviral effects against COVID-19. ${ }^{50,51}$

\section{AUTHOR INFORMATION}

\section{Corresponding Author}

*Y.-F. Li

Email address: liyf@ihep.ac.cn

Notes

The authors declare no competing financial interest.

\section{REFERENCES}

1. H. Haraguchi, J. Anal. At. Spectrom., 2004, 19, 5-14. https://doi.org/10.1039/b308213j

2. H. Haraguchi and H. Matsuura, Proceedings of International Symposium on Bio-Trace Elements 2002 (BITRE 2002) Wako.

3. R. J. P. Williams, Coord. Chem. Rev., 2001, 216-217, 583-595. https://doi.org/10.1016/S0010-8545(00)00398-2

4. R. Lobinski, J. S. Becker, H. Haraguchi, and B. Sarkar, Pure Appl. Chem., 2010, 82, 490-504.

https://doi.org/10.1351/PAC-REP-09-03-04

5. R. G. Ge and H. Z. Sun, Sci. Sin. Chim., 2009, 52, 2055-2070. https://doi.org/10.1007/s11426-009-0144-6

6. Y.-F. Li, H. Sun, C. Chen, and Z. Chai, Metallomics, Science Press, Beijing. 2016.

7. S. Mounicou, J. Szpunar, and R. Lobinski, Chem. Soc. Rev, 2009, 38, 1119-1138. https://doi.org/10.1039/B713633C

8. C. Chen, Z. Chai, and Y. Gao, Nuclear Analytical Techniques for Metallomics and Metalloproteomics, RSC publishing, Cambridge. 2010.

9. L. Banci, Metallomics and the Cell, Springer Netherlands, Amsterdam. 2013

10. W. Maret, Metallomics: A Primer of Integrated Biometal Science, Imperial Colledge Press, London. 2016.

11. B. Michalke, Metallomics: Analytical Techniques and Speciation Methods, Wiley, Berlin. 2016.

12. Y. Ogra and T. Hirata, Metallomics: Recent Analytical Techniques and Applications, Springer Japan, Tokyo. 2017.

13. M. A. Z. Arruda, Metallomics: The Science of Biometals, Springer 2018.

14. G. Sablok, Plant Metallomics and Functional Omics: A System-Wide Perspecitive, Springer, Berlin. 2020.

15. Y.-F. Li, L. Wang, L. Zhang, and C. Chen, in Nuclear Analytical Techniques for Metallomics and Metalloproteomics, ed. C. Chen, Z. Chai, and Y. Gao, RSC publishing, Cambridge. 2010.

16. B. Wang, W. Y. Feng, Y. L. Zhao, and Z. F. Chai, Metallomics, 2013, 5, 793-803. https://doi.org/10.1039/C3MT00093A

17. Y.-F. Li, Y. X. Gao, Z. F. Chai, and C. Y. Chen, Metallomics, 2014, 6, 220-232. https://doi.org/10.1039/C3MT00316G

18. F. Benetti, L. Bregoli, I. Olivato, and E. Sabbioni, Metallomics, 2014, 6, 729-747. https://doi.org/10.1039/C3MT00167A

19. L. M. Wang, J. T. Zhao, L. W. Cui, Y.-F. Li, B. Li, and C. Y. Chen, Metallomics, 2021, 13, mfab013. https://doi.org/10.1093/mtomcs/mfab013

20. L. G. Hu, B. He, Y. C. Wang, G. B. Jiang, and H. Z. Sun, Chin. Sci. Bull., 2013, 58, 169-176. https://doi.org/10.1007/s11434-012-5496-1

21. J. López-Barea and J. L. Gómez-Ariza, Proteomics, 2006, 6, S51-S62. https://doi.org/10.1002/pmic.200500374

22. L. G. Hu, B. He, and G. B, Jiang, in Metallomics, ed. Y.-F. Li, H. Z. Sun, C. Y. Chen, and Z. F. Chai, Science Press, Beijing. 2016.

23. B. W. Chen, L. G. Hu, B. He, T. G. Luan, and G. B. Jiang, TrAC Trends Anal. Chem., 2020, 126, 115875. https://doi.org/10.1016/j.trac.2020.115875

24. X. Li, T. P. Liu, C. Y. Chang, Y. J. Lei, and X. F. Mao, J. Agr. Food. Chem., 2021, 69, 6100-6118. https://doi.org/10.1021/acs.jafc.1c00275 
25. M. Y. Pan, Y. Zang, X. R. Zhou, Y. L. Lu, J. P. Xiong, H. M. Li, and L. X. Feng, At. Spectrosc., 2021, 42, 262-270. https://doi.org/10.46770/AS.2021.104

26. X. H. Song, H. L. Li, C. Ma, W. Y. Duan, Y. B. Sun, Y. Q. Li, T. H. Huang, and B. Zhou, At. Spectrosc., 2021, 42, 278-281. https://doi.org/10.46770/AS.2021.103

27. Y. H. Liang, Y. H. Liu, H. Li, X. Bai, X. Y. Yan, J. T. Zhao, and Y. X. Gao, At. Spectrosc., 2021, 42, 254-261. https://doi.org/10.46770/AS.2021.105

28. Q. Li, Z. Q. Cai, Y. Fang, and Z. Wang, At. Spectrosc, 2021, 42, 238-246. https://doi.org/10.46770/AS.2021.101

29. L. Li, L. T. Yan, H. Y. Sun, Y. Zhou, and X. Q. Feng, At. Spectrosc., 2021, 42, 247-253. https://doi.org/10.46770/AS.2021.107

30. Y. Q. Li, L. Y. Liu, W. D. Chen, and L. J. An, Sci. Sin. Chim., 2018, 48, 243-255. https://doi.org/10.1360/N032017-00182

31. J. H. Li, R. Pei, F. F. Teng, H. Qiu, R. Tagle, Q. Q. Yan, Q. Wang, X. L. Chu, and X. Xu, At. Spectrosc., 2021, 42, 1-11. https://doi.org/10.46770/AS.2021.01.001

32. R. Joannes-Boyau, J. W. Adams, C. Austin, M. Arora, I. Moffat, A. I. R. Herries, M. P. Tonge, S. Benazzi, A. R. Evans, O. Kullmer, S. Wroe, A. Dosseto, and L. Fiorenza, Nature, 2019, 572, 112-115. https://doi.org/10.1038/s41586-019-1370-5

33. X. Wan, C. H. Li, H. P. Wang, W. M. Xu, J. J. Jia, Y. J. Xin, H. Z. Ma, P. P. Fang, and Z. C. Ling, At. Spectrosc., 2021, 42, inpress. https://doi.org/10.46770/AS.2021.608

34. Y.-F. Li, Y. X. Gao, C. C. Chen, B. Li, Y. L. Zhao, and Z. F. Chai, Sci. Sin. Chim., 2009, 39, 580-589. https://doi.org/10.1360/zb2009-39-7-580

35. K. Schilling, F. Larner, A. Saad, R. Roberts, H. M. Kocher, O. Blyuss, A. N. Halliday, and T. Crnogorac-Jurcevic, Metallomics, 2020, 12, 752-757. https://doi.org/10.1039/D0MT00061B.

36. K. Y. Chen, H. L. Yuan, Z. A. Bao, and N. Lv, At. Spectrosc., 2021, 42, 282-293. https://doi.org/10.46770/AS.2021.703

37. R. A. Althobiti and D. Beauchemin, At. Spectrosc., 2021, 42 271-277. https://doi.org/10.46770/AS.2021.708

38. H. Q. Hu, J. T. Zhao, L. M. Wang, L. H. Shang, L. W. Cui, Y. X. Gao, B. Li, and Y.-F. Li, TrAC Trends Anal. Chem., 2020, 122, 115721. https://doi.org/10.1016/j.trac.2019.115721
39. C. Y. Chen, Y.-F. Li, Y. Qu, Z. F. Chai, and Y. L. Zhao, Chem. Soc. Rev., 2013, 42, 8266-8303. https://doi.org/10.1039/C3CS60111K

40. Y.-F. Li, J. T. Zhao, Y. Qu, Y. X. Gao, Z. H. Guo, Z. L. Liu, Y. L. Zhao, and C. Y. Chen, Nanomed. Nanotechnol. Biol. Med., 2015, 11, 1531-1549. https://doi.org/10.1016/j.nano.2015.04.008

41. I. Umegaki, Y. Higuchi, Y. Kondo, K. Ninomiya, S. Takeshita, M. Tampo, H. Nakano, H. Oka, J. Sugiyama, M. K. Kubo, and Y. Miyake, Anal. Chem., 2020, 92, 8194-8200. https://doi.org/10.1021/acs.analchem.0c00370

42. J. H. Liu, L. N. Zheng, J. W. Shi, X. Wei, X. Li, M. L. Chen, M. Wang, J. H. Wang, and W. Y. Feng, At. Spectrosc., 2021, 42, 114-119. https://doi.org/10.46770/AS.2021.102

43. L. N. Zheng, L. X. Feng, J. W. Shi, H. Q. Chen, B. Wang, M. Wang, H. F. Wang, and W. Y. Feng, Anal. Chem., 2020, 92, 14339-14345. https://doi.org/10.1021/acs.analchem.0c01775

44. L. Yan, Y.-F. Li, and Z. Gu, in Toxicology of Nanomaterials, ed. Y. L. Zhao, Z. Zhang, and W. Y. Feng, Wiley. 2016.

45. J. Szpunar, Analyst, 2005, 130, 442-465. https://doi.org/10.1039/B418265K

46. X. Y. Lin, J. T. Zhao, W. Zhang, L. N. He, L. M. Wang, H. Li, Q. C. Liu, L. W. Cui, Y. X. Gao, C. Y. Chen, B. Li, and Y.-F. Li, J. Hazard. Mater, 2021, 409, 124923. https://doi.org/10.1016/j.jhazmat.2020.124923

47. X. Y. Lin, L. M. Wang, J. T. Zhao, L. N. He, L. W. Cui, Y. X. Gao, C. Y. Chen, Y. Q. Fan, B. Li, and Y.-F. Li, Nano Today, 2021, 36, 101010. https://doi.org/10.1016/j.nantod.2020.101010

48. J. T. Zhao, L. M. Wang, L. W. Cui, H. Z. Sun, Y. X. Gao, B. Li, and Y.-F. Li, At. Spectrosc., 2021, 42, 231-237. https://doi.org/10.46770/AS.2021.805

49. S. F. Yuan, R. M. Wang, J. F.-W. Chan, A. J. X. Zhang, T. F. Cheng, K. K.-H. Chik, Z.-W. Ye, S. Y. Wang, A. C.-Y. Lee, L. J. Jin, H. Y. Li, D.-Y. Jin, K.-Y. Yuen, and H. Z. Sun, Nat. Microbiol., 2020, 5, 1439-1448. https://doi.org/10.1038/s41564-020-00802-x

50. L. N. He, J. T. Zhao, L. M. Wang, Q. C. Liu, Y. Q. Fan, B. Li, Y.-L. Yu, C. Y. Chen, and Y.-F. Li, Nano Today, 2021, 36, 101037. https://doi.org/10.1016/j.nantod.2020.101037

51. Q. Y. Liu, X. L. Zhao, J. Ma, Y. S. Mu, Y. Wang, S. H. Yang, Y. H. Wu, F. C. Wu, and Y. Z. Zhou, Environ. Res., 2021, 196, 110984. https://doi.org/10.1016/j.envres.2021.110984 